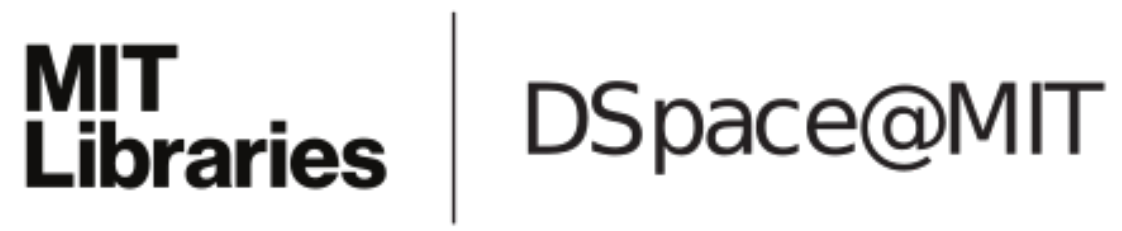

\author{
MIT Open Access Articles
}

Wireless power transmission for medical applications

The MIT Faculty has made this article openly available. Please share how this access benefits you. Your story matters.

Citation: Payne, Josh et al. "Wireless power transmission for medical applications." Nanosensors, Biosensors, and Info-Tech Sensors and Systems 2009. Ed. Vijay K. Varadan. San Diego, CA, USA: SPIE, 2009. 72910X-9. ( 2009 SPIE

As Published: http://dx.doi.org/10.1117/12.816020

Publisher: Society of Photo-Optical Instrumentation Engineers

Persistent URL: http://hdl.handle.net/1721.1/52633

Version: Final published version: final published article, as it appeared in a journal, conference proceedings, or other formally published context

Terms of Use: Article is made available in accordance with the publisher's policy and may be subject to US copyright law. Please refer to the publisher's site for terms of use. 


\title{
Wireless power transmission for medical applications
}

\author{
Josh Payne, Kyo D. Song*, Sang Y. Yang**, Jaehwan Kim**, Yeonjoon Park***, and \\ Sang H. Choi*** \\ Massachusetts Institute of Technology \\ *Department of Engineering \\ Norfolk State University \\ Norfolk, VA 23504 \\ **Center for EAPap Actuator, Mechanical Engineering \\ Inha University, Incheon, Korea \\ ***NASA Langley Research Center \\ Hampton, VA 23681-2199
}

We studied the wireless power transmission capabilities of microwave through human skin-tissue. Microwave transmission through simulated human skins was tested with rectenna array as a power receiver located under the simulated human skin tissue. Most of transplanted medical devices and sensors require power to operate autonomously but currently by imbedded battery. Wireless power transmission alleviates the needs of imbedded power source and hard-wire power network. We used human skin-like materials, such as various polyurethanes and pork skin, under X-band microwave exposure. Transmission rate through various polyurethanes under the threshold limit value (TLV) and dielectric constant was measured in this experiment. It is also critical to measure specific absorption rates (SAR) of polyurethanes and transmission rates through polyurethanes as well as pork skin. This paper presents power transmission rates under varying thickness of polyurethanes, and effectiveness and efficiency of rectennas under the TLV of microwave power. In addition, we will discuss milimeter wave thermograph and hazards the absorption characteristics of human skin under 8-13 GHz using the results of polyurethanes and pork skin.

Keywords: Microwave, Power transmission, Dielectric Constant, Transmission Rates

\section{Introduction}

The use of microwave power system has been demonstrated for smart actuators and devices to provide flexible maneuverability for aero-vehicles and robots [1-7]. This system provides an alternative power/energy source feed by wireless power transmission mechanism. The feasibility studies and development of the integrated

Nanosensors, Biosensors, and Info-Tech Sensors and Systems 2009, edited by Vijay K. Varadan, Proc. of SPIE Vol. 7291, 72910X - (C) 2009 SPIE - CCC code: 0277-786X/09/\$18 - doi: 10.1117/12.816020 
system brought forth with power allocation and distribution (PAD) concept in conjunction with power control circuits [8-9]. Recently, there have been many scientific researches for developing bio-sensors in medical applications [10-12] such as measurement of glucose level in human body or health-monitoring sensors. However, these researches have not addressed power requirements for microsensors in practical applications. Here we address the wireless power transmission technology as one of strong candidate power source for medical applications. In medical applications, the safety under the exposure of microwave is a critical element to be clarified with intensive studies. In assessment study, both the hazard level that such exposure may entail and the safe power transmission to the embedded devices are clearly and effectively answered. There were many researches under development to understand an interaction of biological substances with handset antenna [13-14]. In this paper, we tested the interactions between rectennas and human body using polyurethane and pig skins as simulant. Specifically, we address the following issues: 1) to what extent the effect on human body with X-band microwaves; 2) how well do SAR's limit through materials reaches on rectennas; 3) how different design affects on the performance in determine of wireless power transmission for medical applications.

\section{Rectenna Design and Experiment}

A patch rectenna was designed by aligning two microstrip antenna perpendicularly, and a square patch that has slots located on the microstip. The patch and the microstrips were fabricated on a flexible membrane on which they were connected via Schottky diodes and capacitors. This configuration will mitigate the polarization effect of microstrip antenna. A patch rectenna was fabricated on polyimide membrane. Rectenna was made of 20 micron-copper strip coated on 18 um-thick polyimide membrane. The patch and microstrip patterns were made on both sides of the polyimide membrane by a wet etching technique. Dielectric constant of the polyimide membrane is 3.48 at $2 \mathrm{GHz}$. The Schottky diode was MA2054 series of MA-COM, which has 0.25 0.35 $\mathrm{V}_{\text {Forward }} @ \mathrm{I}_{\mathrm{F}}=1 \mathrm{~mA}, \mathrm{I}_{\text {Reverse }}=100 \mathrm{nA} @ 1 \mathrm{~V}_{\mathrm{R}}$.

A test-bed for the experiment was set up as shown in Fig. 1 (a) and measured the output voltages and currents by using a $20 \mathrm{~W}$ amplifier microwave. A combination of signal generator and amplifier provides $20 \mathrm{~W}$ of microwave power to the Narda horn antenna at a frequency range set at $7-18 \mathrm{GHz}$. The $20 \mathrm{~W}$ microwave power was delivered through a TWT waveguide connected with a rectangular horn. This microwave power will be irradiated on various rectenna array fabricated for various applications. The voltage and current output of rectenna are produced by a microwave power through various polyurethanes and pig skin, and measured their outputs as shown in fig 1. (b) and (c). All other items listed in the equipment and material section were externally placed and connected to the horn antenna and the rectenna via a backplate at the rear of the chamber. The Narda horn antenna was connected to the $20 \mathrm{~W}$ amplifier by a waveguide, and again to the signal generator a coaxial cable. The polyimide rectenna arrays were connected to a power 
measurement system that was located at the exterior of the anechoic chamber by means of a dual output BNC connector. The distances between the horn antenna and the rectenna arrays varied as $10-70$ inches.

\section{Results and Discussions}

The performance of various vertically polarized patched rectenna $(2 \mathrm{~cm} \times 6.5 \mathrm{~cm})$ was tested with a $20 \mathrm{~W}$ microwave amplifier in the anechoic chamber. The $20 \mathrm{~W}$ microwave amplifier was used to irradiate the microwave through the horn antenna. Figures 2 and 3 show the output voltage and current of the rectenna array when the array was placed from 10" to 70" from the form. The rectenna was positioned to the vertical direction. The results of output show $10 \mathrm{VDC}$ and $2.5 \mathrm{~mA}$ from the

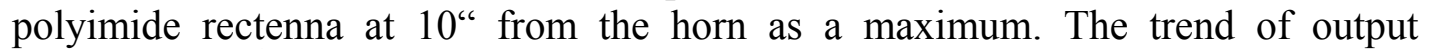
reduced by $1 / \mathrm{r}^{2}$ rule as the distance is increased. However, the output current of the rectenna shows that there is no significant preferential output trends in term of frequencies at distance of 10 " due to near field effects. As the distance is increased, the output shows a clear maximum at $9 \mathrm{GHz}$ instead of $10 \mathrm{GHz}$. In terms of output power, Fig 4 shows a distinguish preferential output as approximately $25 \mathrm{~mW} / \mathrm{cm}^{2}$ at 9 and $10 \mathrm{GHz}$. The optimum output power at $10 \mathrm{GHz}$ under the TLV [15] showed approximately $12 \mathrm{~mW} / \mathrm{cm}^{2}$ at 20 " of the distance.

The rectenna was designed for $10 \mathrm{GHz}$, the output of current is approximately 12 $\mathrm{mA}$ at $10 \mathrm{GHz}$ while the voltage output showed $3.5 \mathrm{VDC}$. With various polyurethanes, the output voltages at 40 " distance from the horn were measured as shown in fig. 5. The absorption coefficient of the microwave through polyurethanes could be calculated based on the result.

The attenuation of the electric field through materials can be calculated as,

$$
\left|E^{\prime}(\mathrm{z})\right|-E_{\phi}-\kappa \pi \quad(\mathrm{v} / \mathrm{m})
$$

Where, $\mathrm{z}$ is the thickness of the materials. The attenuation constant, $\alpha$, is given in Nepers/meter. The effective units of $\alpha$ are then $1 / \mathrm{m}$, so that $\alpha z$ is unit less.

Power is proportional to the square of the electric field, so the power as a function of distance from the initial point, $\mathrm{P}_{\mathrm{o}}$, is calculated as:

$$
|P(z)|=P_{n} e^{-2 \alpha z}(\mathrm{~W})
$$

Based on the result, the absorption coefficients of polyurethanes varies from 0.3 to $0.5 \mathrm{~mm}^{-1}$ while the $\alpha$ for the pig skin varies from 1.1 to $2.5 \mathrm{~mm}^{-1}$ depends on the frequencies. 
With various polyurethanes, the output voltages at 40" distance from the horn were measured as shown in fig. 5. The transmission of the microwave could be calculated based on the result. The output voltages of the rectenna behavior through various polyurethanes were in similar with the output through without the materials on various frequencies. However, at near 9 to $10.5 \mathrm{GHz}$ ranges, the output voltages significant decreased as much as $50 \%$ in one inches thickness. Since the Threshold Limit Value (TLV) for $10 \mathrm{GHz}$ is approximately $10 \mathrm{~mW} / \mathrm{cm}^{2}$, the experimental was performed under the TLV level. Fig. 6 showed output voltages of polyimide rectenna through a pig skin (0.067 to 0.90 " thickness) at various distances. The output voltages decreased rapidly especially at 9 to $10 \mathrm{GHz}$ ranges. The outputs powers of polyimide rectenna through the pig skin $(1.7 \mathrm{~mm}$ to $2.2 \mathrm{~mm})$ are shown in figure 7. It shows a significant absorption over $10.5 \mathrm{GHz}$ frequencies, but the transmission at the 9 to $10 \mathrm{GHz}$ showed preferential result. The transmission rate of the output voltages varied 8 to $43 \%$. The output power is also plotted in figure 7 in a logarithm scale. The transmission rate of the output power varied from $3 \%$ to 31 $\%$. A maximum transmission rate of $31 \%$ was achieved at $8.5 \mathrm{GHz}$ while the transmission rate of $12 \%$ was achieved at $10 \mathrm{GHz}$.

\section{Conclusions}

The two different types of materials such as polyurethanes and pig skin used in simulation of human skin-tissues have tested with microwave power in ranges of 8 to $12.5 \mathrm{GHz}$. Absorption coefficients of those materials on various frequency ranges have measured. Based on the result of the experiment, the absorption coefficients of polyurethanes varies from 0.3 to $0.5 \mathrm{~mm}^{-1}$ while the $\alpha$ for the pig skin varies from 1.1 to $2.5 \mathrm{~mm}^{-1}$ depends on the frequencies. Typically, the skin depth $(=1 / \alpha)$ at 10 $\mathrm{GHz}$ is about $1.7 \mathrm{~mm}$ for the pig skin, while the polyurethane is about $2.5 \mathrm{~mm}$. The result showed significant different absorption coefficients depends on materials or frequencies. Therefore, microwave transmission through simulated human skins need to be carefully tested with various human skin tissue, muscle, and heads in terms of TLV and SAR (specific absorption rate) of all parts.

\section{References}

[1] Song, Kyo D, Yi, Won J., Chu, Sang Hyon and Choi, Sang H., "Microwave Driven THUNDER Materials," Microwave and Optical Technology Letters, Volume 36, Number 5, (2003).

[2] Choi, Sang H., Song, Kyo D., King, Glen, Chu, Sang Hyon, "Microwave power for smart material actuators," Journal of Smart. Mater. Struct. Vol. 13, pp38-48, (2003).

[3] Kim, Jaehwan, Yang, Sang Yeol, Song, Kyo D., Jones, Sean, and Choi, Sang H., "Performance characterization of flexible dipole rectennas for smart actuator 
use," Journal of Smart Materials and Structures, Institution of Physics Publishing, Vo. 15, 809-815, (2006).

[4] Stout, Thomas B., Basappa, Prathap, Williams, Frances, Kim, Jaehwan, and Song, Kyo D., "Study on Microwave Power via Rectenna for Airship Applications," SPIE Conference, San Diego, CA, March 11 -13, (2008).

[5] Brown, W. C., "Experiments involving a microwave beam to power and position a helicopter," IEEE Trans. Aerosp. Electron. Syst., Vol. AES-5, No. 5, pp. 692-702, (1969).

[6] NASA JPL, "Patch Rectenna for Converting Microwave to DC Power," NASA Tech Briefs, Vol. 21, January, p. 40, (1997).

[7] Song, Kyo D. Song, Sang H. Choi, Walter T. Golembiewski, Kevin Henderson, and Glen King, "Remotely Power Feed and Control Devices for Biomimic Robots,"Bio-nano \& Quantum Technology Devices, 2004 Second World Congress on Biomimetic, Artificial Muscles and Nano-Bio, Albuquerque, New Mexico, December 6 - 8, 2004

[8] Kyo D. Song, "Extending PAD (Power Allocation and Distribution)," SPIE (International Optical Engineering Society) Proceeding Paper Number 5763-04, San Diego, CA, March 6-10, 2005

[9] Kyo D. Song, Walter Golembiewski, and Sang H. Choi, "Design of Power Allocation and Distribution Circuit with Rectenna Array for Smart Material Actuators International Symposium on Smart Structures and Microsystems 2000, October $19-21,2000$, The Jockey Club, Hong Kong

[10] J. Abraham , R. Chintakuntla, H. Yoon, and V. Varadan, "Nanowire Integrated Microelectrode Arrays for Neuroelectronic Applications, IEEE Regio \% Technicial Conference, PP 185, April 20-21, 2007

[11] S. Iguuchi, et al., " A flexible and wearable biosensor for tear glucose measurement, Biomed. Microdevices , 9:603-309, 2007.

[12] K. Wassum, et al., "Silicon Wafer-Based Platinum Microelectrode Array Biosensor for Near Real-Time Measurement of Glutamate in Vivo," Sensor 2008, 8, 5023-5036.

[13] Michal Okoniewski and Maria Stuchly, “ A Study of the Handset Antenna and Human Body Interaction," IEEE Transaction on Microwave Theory and Techniques, Vol. 44, No.10, October, 1996.

[14] M. A. Stuchly, "Wireless communications and the safety of the user," Int. J. Wireless Information, Vol. 1, pp 223-228, 1994.

[15] ANSI C95-1992," American National Standard Safety levels with respect to human exposure to radio frequency electromagnetic fields, $300 \mathrm{kHz}$ to $100 \mathrm{GHz}$," New York; IEEE, 1991. 

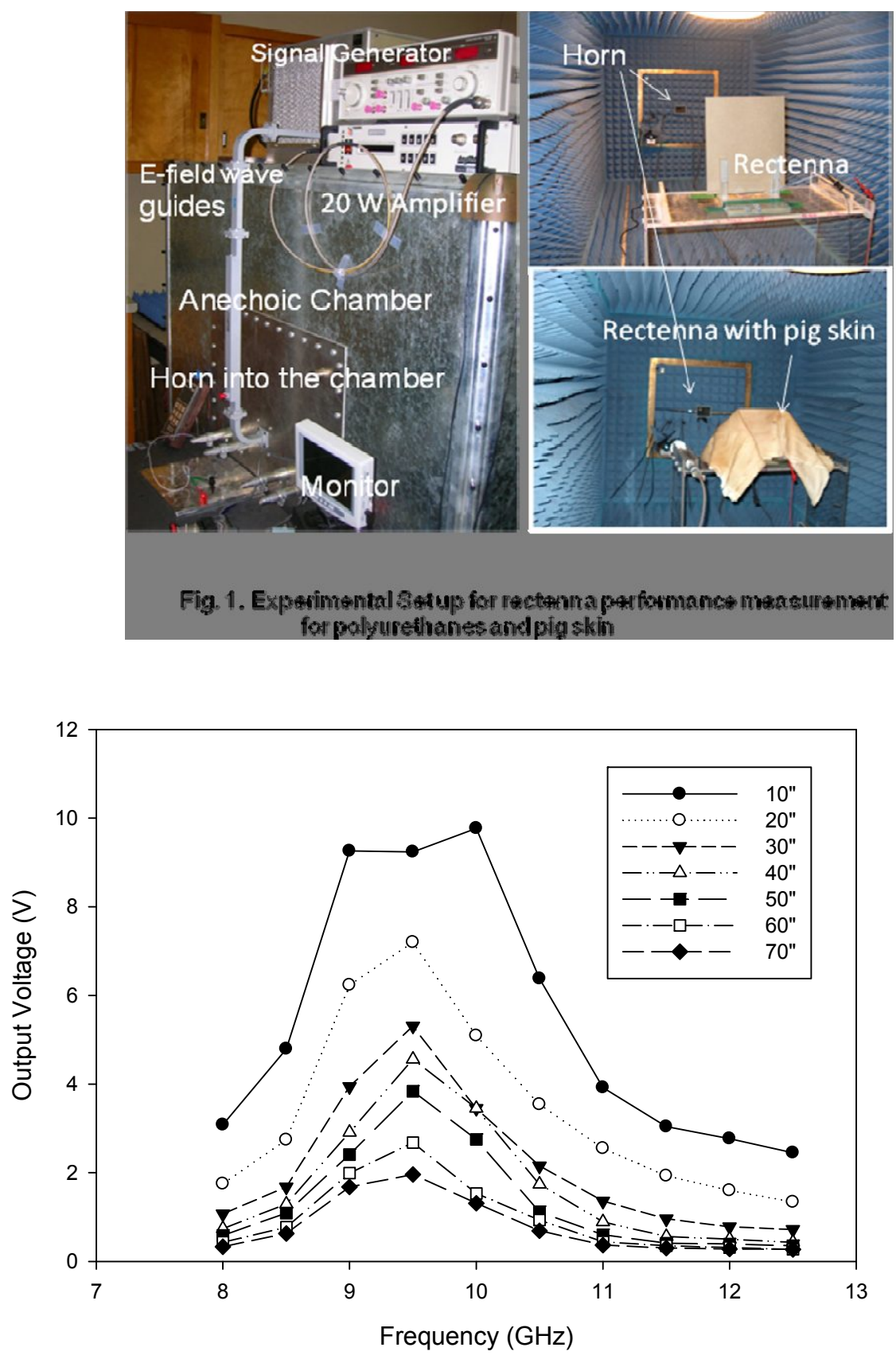

Fig. 2. Output Voltage of Polyimide Rectenna vs Distances from the Horn 


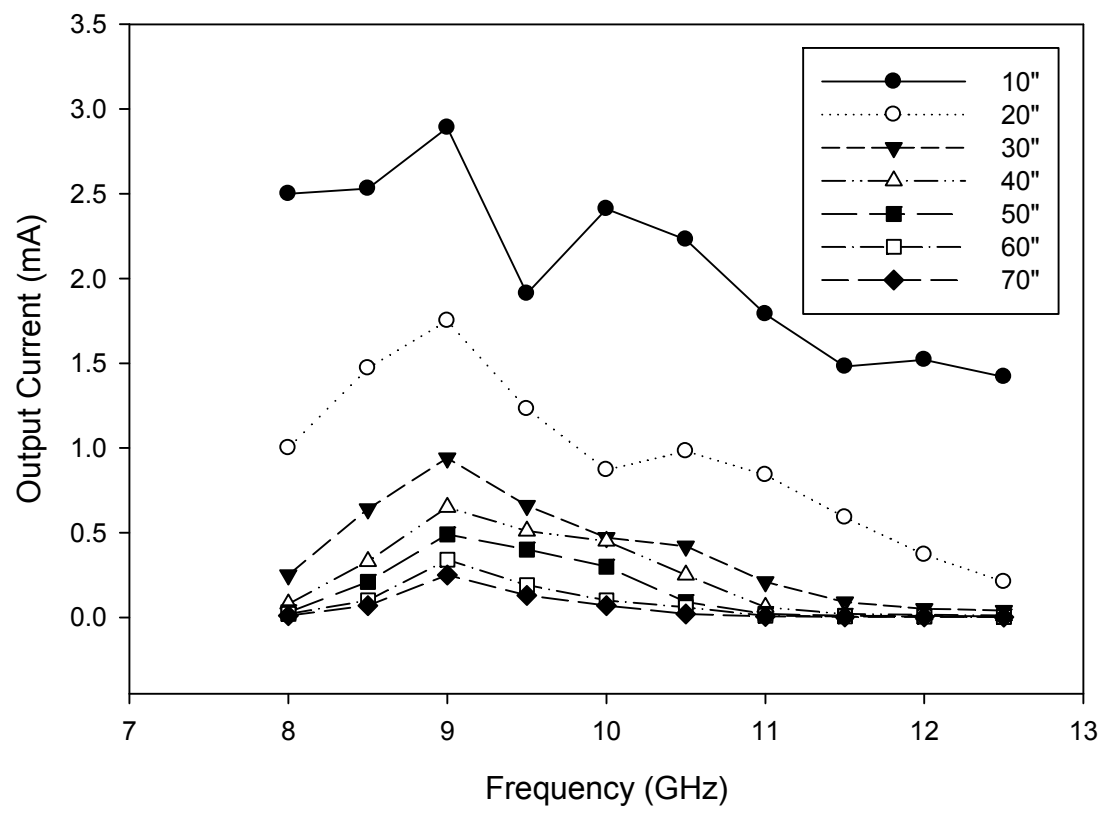

Fig. 3. Output Current of Polymide Rectenna vs. Distances from the Horn

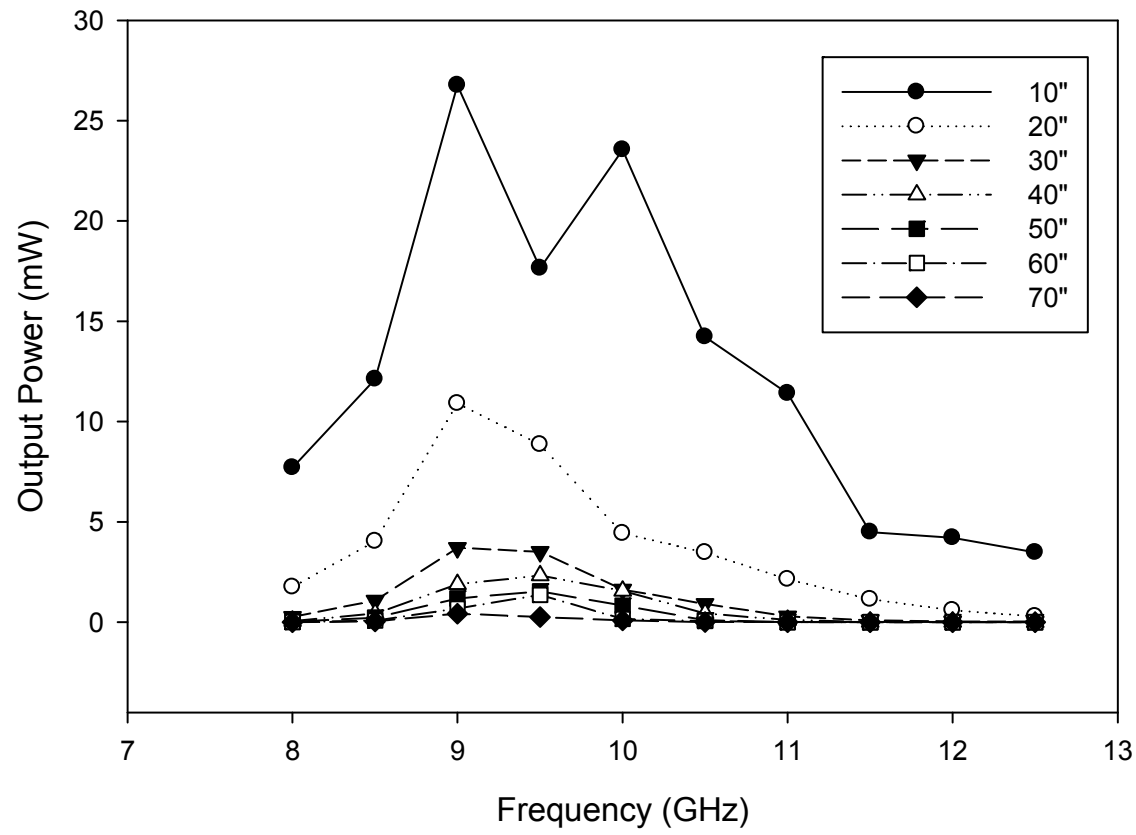

Fig. 4. Output Power of Polyimide Rectenna vs Distances 


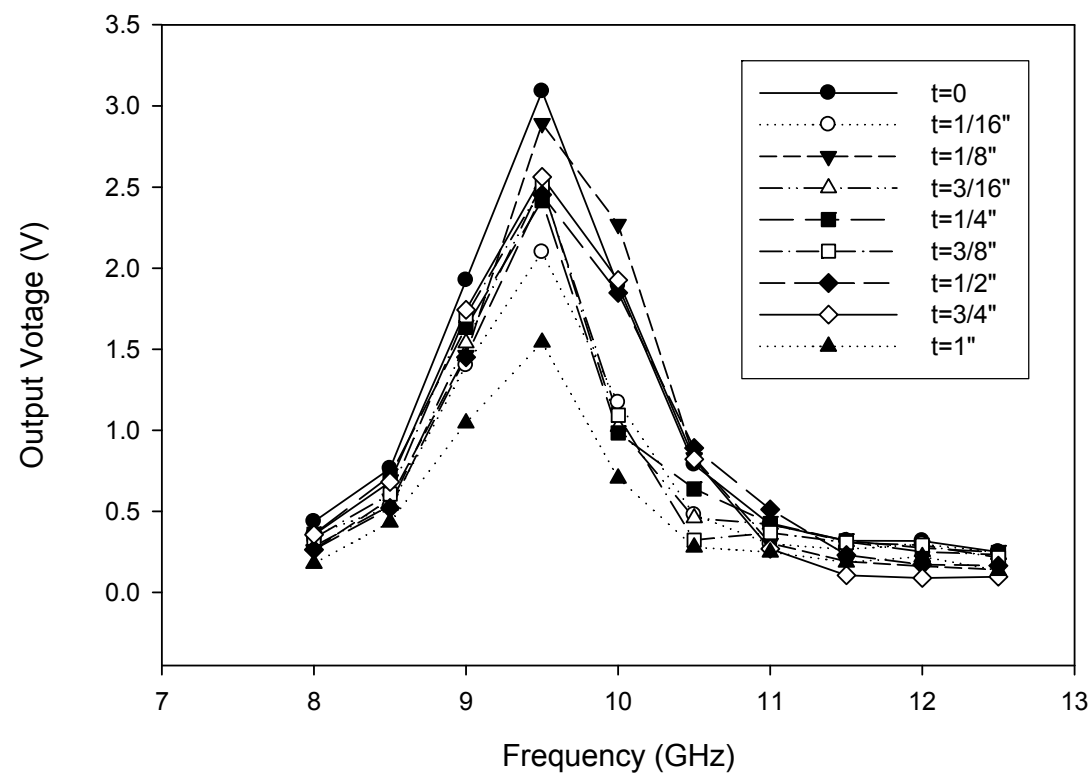

Fig. 5. Output Voltage of Polyimide Rectenna through Various thicknesses of Polyurethanes

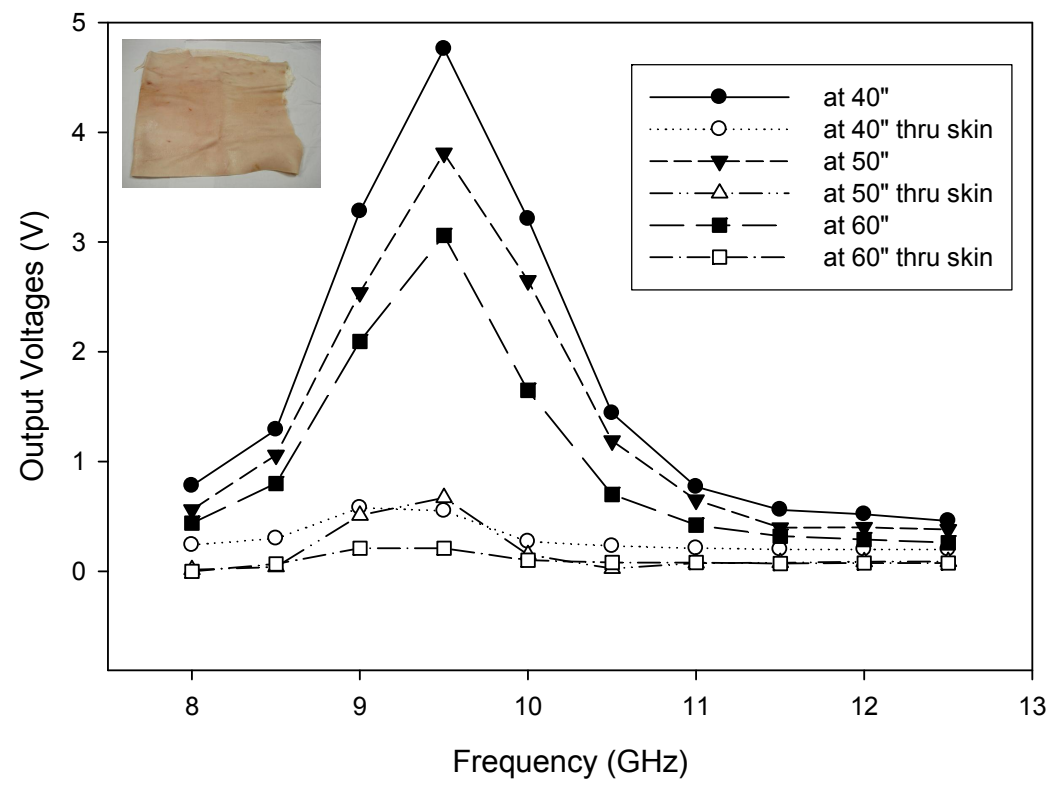

Fig. 6. Output Volatge of Polyimide Rectenna through a pig skin $(t=0.067-0.90 ")$ 


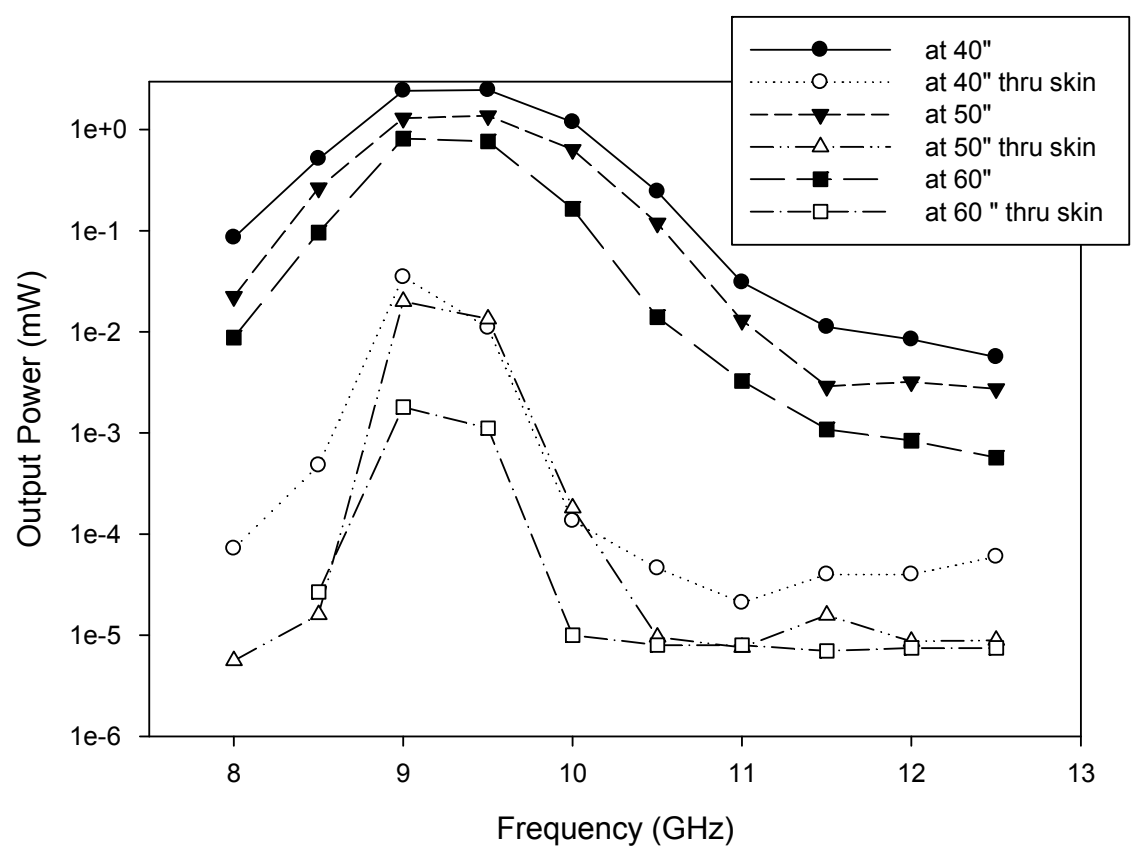

Fig. 7. Output Power of Polymide Rectenna with pig skin and without the skin 